\title{
LOS AÑOS INICIALES DE LA INTERVENCIÓN BÉLICA HOLANDESA EN BRASIL, 1621-1635
}

\author{
The Early Years of the Dutch Military Intervention in Brazil, 1621-1635
}

\author{
Enrique Garrido Díez de BALdeón \\ Universidad de Salamanca \\ enrique88ba@hotmail.com
}

Fecha de recepción: $19-\mathrm{I}-2013$

Fecha de aceptación: 4-V-2013

RESUMEN: El trabajo presentado en estas líneas supone un recorrido histórico por los primeros años de actividad militar holandesa en Brasil durante el siglo XVII. Un estudio en el que se analizan las razones que llevaron a los Países Bajos a emprender acciones contra la colonia luso-española, el papel protagonista de la Compañía de las Indias Occidentales -WIC-, las intervenciones militares y de conquista desarrolladas por los holandeses en el nordeste brasileño y las iniciativas de contraofensiva ibérica. Todo ello prestando especial atención a las diversas fases que atravesó la guerra y a la ineficacia de numerosas tácticas y estrategias militares europeas sobre suelo americano.

Palabras clave: Brasil, Países Bajos, Monarquía Ibérica, Compañía de las Indias Occidentales, conflicto bélico, expansión atlántica.

ABSTRACT: The work presented in these lines is a historical journey through the early years of the Dutch military activity in Brazil. A study that analyzed the reasons which made the Netherlands take action against the Portuguese-Spanish colony, the main role of the West India Company -WIC-, the military intervention and conquest developed by the Dutch in the Brazilian Northeast and the Iberian counter initiatives. Special attention is given to the various stages which spanned the war and the failure of many European military tactics and strategy on American soil.

Keywords: Brazil, Netherlands, Iberian Monarchy, Dutch West India Company, Warlike conflict, Atlantic expansion. 
La guerra no es sino la continuación de la politica por otros medios. Clausewitz, $1807^{1}$.

A nadie resulta extraño que el siglo XVII, para el caso europeo, supone un período convulso y conflictivo caracterizado, entre otras cosas, por el constante redoblar de los tambores, la armonizada marcha de los tercios o el, siempre temido, rugir de los cańones y arcabuces. En estos años, el viejo continente no era sino un gran teatro cuyo actor protagonista era la guerra a gran escala.

Prácticamente ninguna región estaba exenta de conflictos, todas desempeñaban algún rol en un juego de ajedrez político que en numerosas ocasiones escapaba al control de los propios jugadores. Dentro de esta confusión bélica, la Monarquía Hispánica, protagonista indiscutible en casi todos los enfrentamientos, jugaba un papel destacado. Era el enemigo a batir, un gigante con pies de barro cuyas finanzas languidecían con la misma premura con que se granjeaba enemigos.

Muchos eran los frentes que los Habsburgo de Madrid tenían abiertos en Europa, pero sin duda el más peligroso, tanto por su duración como por el elevado coste financiero y humano de él derivado, era el que enfrentaba a la casa de Austria con los Países Bajos desde 1568. Flandes fue un quebradero de cabeza insostenible, un cenagal frío y húmedo en el que la Monarquía Hispánica se desangró poco a poco, mientras su prestigio y el brillo dorado de sus años de gloria se desvanecían.

\section{BRASIL: UN NUEVO ESCENARIO PARA LA GUERRA CON LOS PAÍSES BAJOS}

Es precisamente en este contexto de guerra con los Países Bajos -conflicto que como apunta Geoffrey Parker duró más tiempo que ningún otro levantamiento en la historia de la Europa moderna ${ }^{2}$ - donde se inscriben los desvelos ultramarinos holandeses y la empresa bélica desplegada en el nordeste brasileńo. Una jugada astuta y arriesgada que, planeada y ejecutada por la West-Indische Compagnie -WIC- con el apoyo de los Estados Generales, perseguía trasladar a la esfera colonial un conflicto europeo que comenzaba a fatigar en exceso a ambos contendientes. No obstante, presentar con esta parquedad y simplificación tamańo suceso supone constreñir deliberadamente una realidad cuyos detonantes, objetivos y desarrollos, tanto previos como posteriores, distan de ser sencillos.

1 Albi de la Cuesta, Julio. De Pavía a Rocroi; los tercios de infantería española en los siglos XVI y XVII. Madrid: Balkan Editores, 1999, p. 11.

2 PArker, Geoffrey. España y los Países Bajos, 1559-1659. Madrid: Rialp, 1986, p. 53. 
Mucho se ha debatido acerca de las razones o motivos que llevaron a los holandeses a conquistar Pernambuco junto con otras cinco capitanías donatarias del nordeste azucarero. Algunos autores como Georg Friedrich Preuss apuntan que la expedición holandesa a las Indias fue el efecto de una explosión irrefrenable de confianza y éxito por parte de un pueblo con gran tradición marinera que estaba experimentando una fuerte bonanza económica ${ }^{3}$. Petrus Johannes Blok y Hermann Wätjen, por su parte, sostienen que además de estas causas influyó, enormemente, el deseo, por parte de los Países Bajos, de llevar la guerra a las colonias de la Monarquía Hispánica y de interceptar las comunicaciones entre el territorio ultramarino y la metrópolí. Otros historiadores como José Manuel Santos y George F. Cabral de Souza constatan una doble finalidad: mermar la capacidad económica de los Austrias e incrementar el dominio holandés sobre las rutas comerciales del Atlántico 5 . A estas motivaciones hay que añadir, tal y como subrayan autores de la talla de Jonathan Israel o Evaldo Cabral de Mello, que, con el fin de la Tregua de los Doce Años en 1621, numerosos veleros neerlandeses fueron confiscados en los puertos españoles, desarrollándose nuevos embargos sobre el comercio y la navegación flamenca que provocaron que el intenso tráfico de mercancías que los Países Bajos habían disfrutado en años anteriores fuese, de repente, severamente restringido ${ }^{6}$.

Pero, ¿por qué Brasil? De todos los territorios atlánticos que se encontraban bajo el dominio de la Monarquía Ibérica ¿qué llevó a los holandeses a encaminar sus pasos hacia el nordeste brasileño? La respuesta es sencilla, no existía en el continente americano región más fácilmente conquistable que la América portuguesa, territorio cuya

3 Wätjen, Hermann. O Dominio Colonial Holandês no Brasil. Recife: Companhia Editora de Pernambuco, 2004, p. 66.

4 Ibidem, p. 68.

5 Santos Pérez, José Manuel; Cabral de Souza, George F. El desafío holandés al dominio ibérico en Brasil en el siglo XVII. Salamanca: Universidad de Salamanca, 2006, p. 9.

6 Tal realidad se observa en Israel, Jonathan I. «El Brasil y la política holandesa en el Nuevo Mundo». En Israel, Jonathan I. [et al.]. Acuarela de Brasil, 500 años después, seis ensayos sobre la realidad histórica y económica brasileña. Salamanca: Ediciones Universidad de Salamanca, 2000, p. 17; también en Cabral de Mello, Evaldo. Olinda restaurada. Guerra e açucar no Nordeste, 1630-1654. Rio de Janeiro: Topbooks, 1975, pp. 53-56; y en Israel, Jonathan I. La República Holandesa y el mundo hispánico, 1606-1661. Madrid: Nerea, 1997, p. 127. Además, hay que señalar también que durante la tregua con la Monarquía Hispánica la presencia flamenca en el mundo colonial portugués avanzó considerablemente. Para el año 1621, los holandeses disfrutaban de un papel destacado en el Atlántico, controlando el 66\% de la navegación, legal o clandestina, desarrollada entre Brasil y Europa. Sin olvidar que eran comerciantes neerlandeses y judíos sefarditas de Ámsterdam - ciudad que contaba, para comienzos del siglo XVII, con 25 refinerías de procesado azucareroquienes compraban y financiaban gran parte del azúcar exportado desde territorio brasileńo. Sin embargo, esta favorable y próspera coyuntura se vio truncada con el fin de la Tregua de los Doce Años en 1621. En Guilherme M., Carlos; López, Adriana. Historia de Brasil: una interpretación. José Manuel Santos Pérez (trad.). Salamanca: Ediciones Universidad de Salamanca, 2009, p. 109. 
vulnerabilidad la hacía atractiva a ojos de los Estados Generales ${ }^{7}$. Entre las razones que se aducen para justificar dicha debilidad encontramos: la escasa disposición de grandes contingentes militares o de fortalezas, tanto en Bahía como en Pernambuco ${ }^{8}$, y la mayor indolencia con la que eran tratadas las posesiones coloniales portuguesas por parte de los Austrias de Madrid?.

\section{LA COMPAÑÍA DE LAS INDIAS OCCIDENTALES Y LA DEBILIDAD DEFENSIVA DEL NORDESTE BRASILEÑO}

Esgrimidos los objetivos y motivos que llevaron a los Países Bajos a afrontar este reto atlántico, así como el teatro de operaciones elegido por los holandeses para actuar, resulta ineludible hablar del brazo ejecutor que se encargó de la culminación de tan ambiciosa empresa, la WIC. Esta Compañía de las Indias Occidentales, fundada por los Estados Generales cuando apenas habían pasado dos meses desde el fin de la Tregua de los Doce Años, se erigió, desde el primer momento, como una organización por acciones que actuaba, ante todo, como un instrumento económico y de lucha política y religiosa ${ }^{10}$. Las competencias que contemplan los estatutos fundacionales de la compañía pasaban esencialmente por la fundación de colonias, el intervencionismo en el tráfico comercial atlántico y el intento de trasladar la guerra entre los Países Bajos y la Monarquía Ibérica al escenario de las regiones ultramarinas ${ }^{11}$. En resumen, con la WIC se produjo una privatización de las operaciones de guerra y de la colonización en el Nuevo Mundo ${ }^{12}$.

Por otro lado, en lo que respecta a las atribuciones de la West-Indische Compagnie hay que considerar que, según su patente, la compañía poseía el monopolio del comercio con los territorios americanos y la costa occidental de África, lo cual implicaba que tenía capacidad para armar su propio ejército y su flota de guerra -no olvidemos que la naturaleza de la compañía era eminentemente bélica ${ }^{13}-$. Además, tenía autorización para firmar contratos y tratados con príncipes nativos en el exterior y la potestad suficiente para nombrar gobernadores y funcionarios ${ }^{14}$. Todos estos privilegios y poderes hacían de la Compañía de las Indias Occidentales una asociación de carácter semi-bélico, organizada para fines de conquista, con derechos soberanos y amplios medios ofensivos y técnicos.

\footnotetext{
En Cabral de Mello, Evaldo. Olinda restaurada [...]. Op. cit. p. 25; y en Wätjen, Hermann. $O$ Dominio Colonial [...]. Op. cit. p. 85.

8 Cabral de Mello, Evaldo. O Brasil holandés. São Paulo: Penguin Classics, 2010, p. 30.

9 WäTJen, Hermann. O Dominio Colonial [...]. Op. cit. p. 85.

10 Israel, Jonathan I. «El Brasil y la política holandesa [...]. Op. cit. p. 14.

11 Wätjen, Hermann. O Dominio Colonial [...]. Op. cit. p. 73.

12 Guilherme M., Carlos; López, Adriana. Historia de Brasil [...]. Op. cit. p. 110.

13 Wätsen, Hermann. O Dominio Colonial [...]. Op. cit. p. 74.

14 Guilherme M., Carlos; López, Adriana. Historia de Brasil [...]. Op. cit. p. 110.
} 
$\mathrm{Al}$ inicio de los ańos veinte del siglo XVII los holandeses ya tenían un objetivo en el punto de mira -el nordeste de Brasil-y el instrumento perfecto para ejecutar el plan de expansión -la WIC-. Pero ¿qué era Brasil en aquella época? Y, lo más importante, ¿cuán real era esta supuesta debilidad que desde la otra orilla del atlántico los flamencos atribuían a la colonia portuguesa?

A principios del siglo XVII, Brasil consistía en una muy larga y estrecha banda costera con unos pocos centros de población y unas aún más escasas fortificaciones entre las que destacaban Bahía, Recife y Río de Janeiro; además, el aparato administrativo, gubernativo y militar era mucho más débil que el de Nueva Espańa o Perú ${ }^{15}$. Una realidad precaria que desde Madrid se intentó mitigar mejorando, tímidamente, la situación de la administración y la defensa de la colonia portuguesa durante los años de unión de las dos coronas ibéricas - período a menudo denostado y olvidado por la historiografía lusa-. La ligazón hispano-portuguesa supuso la puesta en marcha de numerosas medidas de carácter militar, como un gran plan de defensa a lo largo de la costa de Brasil, que contemplaba la construcción de una línea de fortificaciones desde Forte Presépio -actual Belém- hasta Santo Amaro da Barra -en São Paulo-, y mejoras de carácter administrativo que tenían como principal objetivo hacer más eficiente el gobierno del territorio brasileño ${ }^{16}$. Pese a todo, la región siguió mostrándose como un conjunto demográficamente disperso y vulnerable, presentando grandes carencias militares y una más que constatable debilidad político-administrativa, situación que hacía del territorio un atractivo reclamo para los enemigos de la Monarquía Habsbúrgica.

A pesar de esto, el peligro o el miedo a ser atacados no parecía grande. No había indicio alguno, a principios de la década de 1620, que hiciera presagiar que los Países Bajos pasarían a la ofensiva sobre territorio americano en una escala comparable a la del Lejano Oriente ${ }^{17}$. Hasta 1624 los holandeses -sobre todo de Zelanda- tan sólo se habían preocupado por adueñarse, sin mucho éxito, de las salinas de la Costa Salvaje, entre las desembocaduras de los ríos Orinoco y Amazonas ${ }^{18}$. Una iniciativa infructuosa de la que tan sólo cabe destacar, como empresa importante del período, el intento sostenido por las ciudades del norte de Holanda para reanudar el transporte de sal caribeña a gran escala desde Punta de Araya -en la actual Venezuela- en $1623^{19}$.

Sin embargo, los neerlandeses no tardaron en mostrar sus cartas cuando los directores de la Compañía de las Indias Occidentales, los Heren XIX-Diecinueve Señores-,

\footnotetext{
15 Israel, Jonathan I. «El Brasil y la política holandesa [...]. Op. cit. pp. 12-13.

16 Santos PÉrez, José Manuel. «Estado, capitanías donatarias y compañías comerciales». En SAntos Pérez, José Manuel; Cabral de Souza, George F. El desafío holandés [...]. Op. cit. p. 92.

17 Israel, Jonathan I. La República Holandesa [...]. Op. cit. p. 118.

18 Guilherme M., Carlos; López, Adriana. Historia de Brasil [...]. Op. cit. p. 109.

19 Israel, Jonathan I. La República Holandesa [...]. Op. cit. p. 119.
} 
optaron por un rumbo más ambicioso, proyectando un ataque a gran escala sobre Brasil. Esta decisión estuvo motivada por la visión del azúcar, cuya producción anual estimada por la compañía era de unos 5.000.000 de florines, previsión que, junto a la relativa debilidad defensiva del territorio, produjo un hechizo irresistible ${ }^{20}$.

\section{EL INICIO DE LA OFENSIVA HOLANDESA: LA TOMA DE SALVADOR DE BAHÍA Y LA REACCIÓN IBÉRICA}

En 1624 tuvo lugar la primera gran expedición bélica de la WIC contra territorio brasileño. Un ataque dirigido contra la ciudad de Salvador de Bahía, sede del gobierno colonial y del más alto tribunal de justicia, además de principal puerto de la colonia y emporio central de la primera Capitanía Regia ${ }^{21}$. No fue, por tanto, un lugar escogido al azar, lo holandeses sabían donde golpeaban y desarrollaron unos preparativos acordes con la magnitud del despacho. Todo se dispuso minuciosamente y para enero de 1624 una flota compuesta por 26 navíos y 3300 hombres se encontraba armada, equipada y lista para partir ${ }^{22}$. Al mando de la misma se colocó el almirante Jacob Willekens, un antiguo pescadero de Ámsterdam, cuyas instrucciones determinaban que, tomada Bahía, se lanzase también un ataque sobre Pernambuco ${ }^{23}$. Acompañando a Willekens estaban Pieter Pieterszoon Hein, como vice-almirante, y Jan Van Dorth, como comandante general de las tropas de desembarco.

La flota abandonó Holanda en enero de 1624, haciendo acto de presencia en Bahía el 8 de mayo de ese mismo ańo. El contingente comandado por Jan Van Dorth desembarcó al día siguiente bajo el abrigo protector de un bombardeo cerrado sobre la ciudad que aterrorizó a la población, obligándola a abandonar sus casas y adentrarse en el Recôncavo baiano ${ }^{24}$. En tan sólo dos días Salvador de Bahía capituló y el gobernador general Diogo de Mendoça Furtado fue hecho prisionero. No obstante, es necesario señalar que en el momento del ataque la ciudad estaba prácticamente desierta y las tropas

$\overline{20}$ ISRAEL, Jonathan I. La República Holandesa [...]. Op. cit. p. 124.

21 Wätjen, Hermann. O Dominio Colonial [...]. Op. cit. p. 88.

22 Debemos matizar que existen algunas pequeñas discrepancias en cuanto al número de barcos. Mientras Jonathan Israel y Evaldo Cabral de Mello hablan de 26 navíos, algunos de los cuales eran muy rápidos e imponentes, Hermann Wätjen habla de 23. En Israel, Jonathan I. La República Holandesa [...]. Op. cit. p. 124; Cabral de Mello, Evaldo. O Brasil holandés [...]. Op. cit. p. 39; Wätjen, Hermann. O Domínio Colonial [...]. Op. cit. p. 88.

23 Estas instrucciones no hacen sino ratificar las altas pretensiones de la expedición y su objetivo de infringir el mayor daño posible sobre el territorio colonial ibérico, atacando dos de los centros más importantes y pujantes de la región ultramarina. En Cabral de Mello, Evaldo. O Brasil holandés [...]. Op. cit. p. 39.

24 Ibidem. 
de defensa eran insuficientes ${ }^{25}$, sólo un escaso contingente humano formado por negros y cristianos nuevos se interpuso fugazmente entre las tropas neerlandesas y su objetivo de conquista. Esta falta de efectivos por parte de la colonia se debía a que la Monarquía Hispánica, desde Felipe II, se había esforzado en privilegiar el poderío naval frente a la defensa colonial terrestre, que tenía un papel subsidiario ${ }^{26}$. En cuanto al botín de los vencedores, Wätjen estima que las tropas invasoras sustrajeron un total de 3900 cajas de azúcar y mucha madera de tinte ${ }^{27}$.

Pese a la victoria, los holandeses no tardaron en darse cuenta de las dificultades que tendrían para extender su presencia fuera de los muros de Salvador de Bahía. Pronto comenzaron a verse acorralados por las guerrillas luso-brasileńas del arrabal do Rio Vermelho, las cuales, bajo la dirección del obispo Marcos Teixeira, ardiente patriota, y de Francisco de Moura, ofrecieron una dura resistencia a los continuos intentos de incursión de los contingentes bátavos ${ }^{28}$. A partir de ese momento, tuvieron lugar numerosos asaltos y emboscadas que lograron confinar al enemigo dentro de los muros de la ciudad, situación que fue minando la moral y las fuerzas de las tropas neerlandesas.

A esta difícil situación se unió la muerte de Jan Van Dorth, víctima de uno de los ataques sorpresivos lanzados por las guerrillas, y el abandono de la ciudad por parte de la armada de Willekens, que zarpó con dirección a la costa africana junto con dos navíos del vice-almirante Piet Heyn, dejando a las tropas de tierra abandonadas a su suerte y sin ningún apoyo $\operatorname{costero~}^{29}$. La realidad era, por tanto, crítica para los conquistadores holandeses que, hostigados por las fuerzas luso-brasileñas y con las esperanzas y el ánimo deteriorados, necesitaban con premura el auxilio de los Estados Generales.

Mientras tanto, la noticia de lo ocurrido en Bahía, que llegó a la Península un mes antes que a Holanda, provocó una gran consternación en las cortes de Lisboa y Madrid. El 2 de agosto hubo una reunión conjunta del Consejo de Portugal y del Consejo de Estado en donde ministros de la doble monarquía se congregaron para debatir el método de actuación. Los portugueses consideraban que era competencia de sus colegas castellanos correr

25 La hazańa holandesa de 1624 mostró la superioridad enemiga ante la debilidad del nordeste brasileño, que no estaba preparado para resistir las embestidas de los adversarios de los Habsburgo de Madrid. Para tener una idea más aproximada de las múltiples carencias que presentaba la ciudad de Salvador, basta con mencionar que ni tan siquiera contaba, para el año de 1622, con una cárcel segura donde encarcelar prisioneros y las fortificaciones e instalaciones defensivas, así como el contingente militar encargado de las mismas, eran casi inexistentes. En Santaella Stella, Roseli. Brasil durante el gobierno español; 1580-1640. Madrid: Fundación Histórica Tavera, 2000, p. 147. Y en Israel, Jonathan I. La República Holandesa [...]. Op. cit. p. 124.

Cabral de Mello, Evaldo. Olinda restaurada [...]. Op. cit. p. 28.

Wätjen, Hermann. O Domínio Colonial [...]. Op. cit. p. 89.

Ibidem.

Cabral de Mello, Evaldo. O Brasil holandés [...]. Op. cit. p. 39. 
con los gastos derivados de la fuerza bélica que había de enviarse a socorrer Salvador ${ }^{30}$. Por su parte, los Austrias de Madrid consideraron siempre que la financiación de los gastos militares portugueses debía correr por cuenta lusa o, como mucho, ser completados, que no sustituidos, por el dinero de Castilla en caso de insuficiencia ${ }^{31}$. No obstante, pese a estas discrepancias, se actuó con presteza y determinación, reuniéndose rápidamente la mayor armada jamás enviada a América en esa época.

A toda prisa fueron aparejados y armados 52 barcos y 12.500 hombres -de los cuales 30 barcos y casi 8500 soldados eran españoles- y enviados a Bahía bajo el mando del general e ilustre marino Fadrique Álvarez de Toledo ${ }^{32}$. Además, el rey Felipe IV, demostrando una gran astucia estratégica, intensificó sus operaciones sobre los Países Bajos, instando a Ambrosio de Spínola, capitán general del Ejército de Flandes, para que aumentase, paralelamente a esta expedición naval, la actividad de los tercios españoles sobre Breda, intentando así distraer la atención de unos holandeses que, entusiasmados con la toma de Bahía, ya se preparaban para enviar un contingente de apoyo y refuerzo ${ }^{33}$.

La enorme armada ibérica, tripulada por portugueses, españoles y napolitanos ${ }^{34}$, arribó al puerto de Salvador en las vísperas de la Pascua del año 1625, un mes antes de que llegara la flota de refuerzo holandesa. Cuando la desmoralizada guarnición bátava de Salvador vio tan imponente escuadra en el horizonte no tardaron en rendirse a su superioridad, capitulando sin apenas mostrar resistencia u oposición. La ciudad fue recuperada con rapidez y escasa pérdida de efectivos, tornando inútil los esfuerzos de la flota neerlandesa de refresco, que llegó con la ciudad rendida y de nuevo en poder de los Habsburgo de Madrid.

Con la ciudad en manos luso-españolas, el pesimismo sobre el futuro de la West-Indische Compagnie inundó cada rincón de los Países Bajos, haciendo que el valor de sus acciones en la bolsa de Ámsterdam se depreciara considerablemente ${ }^{35}$; una imagen que sin duda contrastaba con la euforia que se vivió en la Monarquía Hispánica ${ }^{36}$. Además, a esto hay que ańadir que la presencia neerlandesa en el Amazonas fue duramente contestada en

\footnotetext{
$30 \quad$ Israel, Jonathan I. La República Holandesa [...]. Op. cit. p. 125.

31 Valladares, Rafael. «Brasil: de la unión de coronas a la crisis de Sacramento (1580-1680)». En Israel, Jonathan I. [et al.]. Acuarela de Brasil [...]. Op. cit. p. 28.

32 Israel, Jonathan I. «El Brasil y la política holandesa [...]. Op. cit. p. 18; Santaella Stella, Roseli. Brasil durante el gobierno [...]. Op. cit. p. 120; Wä́sen, Hermann. O Domínio Colonial [...]. Op. cit. p. 90.

33 Israel, Jonathan I. La República Holandesa [...]. Op. cit. p. 125.

34 Santaella Stella, Roseli. Brasil durante el gobierno [...]. Op. cit. p. 120.

35 Boxer, Charles Ralph. The Dutch in Brazil: 1624-1654. Oxford: Clarendon, 1957, pp. 26-28; Israel, Jonathan I. Dutch primacy in world trade, 1585-1740. Oxford: Clarendon Press, 1989, p. 160.

36 Wätjen, Hermann. O Dominio Colonial [...]. Op. cit. p. 91.
} 
el año 1625 , fecha en que los portugueses lanzaron una ofensiva que condujo a la expulsión de los holandeses de Corupá y de casi todos sus enclaves en el río ${ }^{37}$.

\section{CAMBIO DE RUMBO EN LA POLÍTICA DE EXPANSIÓN ATLÁNTICA DE LA WIC}

Con gran parte de la confianza de los Estados Generales perdida a causa del fracaso de sus primeras empresas, la Compañía de las Indias Occidentales cambió de estrategia en 1626, dejando de lado los planes de conquista a gran escala en Brasil y sustituyéndolos por una táctica de pillaje indiscriminado ${ }^{38}$. En esta fase, que duraría hasta 1630 , la WIC y sus aliados del corso zelandés buscaron compensar los fracasos en Bahía y para ello desarrollaron un ambicioso plan de piratería y sustracción marítima ${ }^{39}$.

Las dos primeras acometidas llegaron en 1627, cuando se encargó a Piet Heyn dirigir una nueva escuadra hacia Bahía de Todos los Santos. En marzo de ese mismo año, la armada holandesa hizo su aparición en la costa baiana, donde entablaron combate con los espańoles y portugueses que, advertidos de la inminente llegada de la flota de Heyn, esperaban al resguardo de las posiciones fortificadas de la ciudad ${ }^{40}$. Tras casi tres horas de dura batalla, con pérdidas considerables en ambos contendientes y con un uso muy limitado de la artillería por parte de las fuerzas luso-españolas, los holandeses pudieron hacerse con el control de numerosos barcos y saquearlos, apoderándose de 2565 cajas de azúcar y abundante botín adicional ${ }^{41}$. Cuatro meses después, un pequeño escuadrón neerlandés interceptó y saqueó en el caribe un galeón español cargado de plata, añil, cacao y otros artículos. En total, la compañía logró capturar 55 barcos en 1627, convirtiéndose así en un verdadero quebradero de cabeza para la flota atlántica de Felipe IV ${ }^{42}$.

Con la armada holandesa cosechando victorias en el Atlántico y acechando los puertos americanos y los galeones que de ellos partían, era sólo cuestión de tiempo que una presa de mayor tamaño acabara cayendo en manos de la compañía. Fue durante el transcurso del año 1628 cuando se alcanzó el cénit de la actividad corsaria y de pillaje neerlandesa, momento en que la WIC y Piet Heyn entraron en los anales de la historia marítima

37 Israel, Jonathan I. La República Holandesa [...]. Op. cit. p. 127.

Ibidem, p. 175.

39 Cabral de Mello, Evaldo. O Brasil holandés [...]. Op. cit. p. 41.

40 Wätjen, Hermann. O Dominio Colonial [...]. Op. cit. p. 91.

41 Es necesario matizar que hay discrepancias a la hora de establecer el número de cajas de azúcar que fueron sustraídas por los holandeses. Hermann Wätjen habla de un total de 2700 cajas, mientras que Jonathan Israel menciona una cantidad de 2565 cajas. En cualquier caso, la cantidad superaba las 2500 cajas, hecho que convertía el botín en una captura importante. En IsRaEL, Jonathan I. La República Holandesa [...]. Op. cit. p. 175. Y en Wätjen, Hermann. O Dominio Colonial [...]. Op. cit. p. 92.

42 Israel, Jonathan I. La República Holandesa [...]. Op. cit. p. 175. 
holandesa con la captura de la Flota Española de la Plata en la bahía de Matanzas, en Cuba, asestando con ello un duro golpe a las convalecientes finanzas de la Monarquía Ibérica y proporcionando a la Compañía de las Indias Occidentales un botín de más de 8 millones de florines, además de oro, pieles y añil ${ }^{43}$. La sustracción de esta importante cantidad de recursos insufló aire y optimismo económico a la WIC, que se vio capaz de hacer frente a la financiación de nuevos proyectos más audaces y ambiciosos. También en este año de 1628 la West-Indische Compagnie ocupó la isla Fernando de Noronha -en el nordeste brasileño-, siendo expulsados por fuerzas enviadas desde Pernambuco en $1629^{44}$.

Sin embargo, pese a las múltiples capturas y los logros marítimos alcanzados por los holandeses en los años 27 y 28, historiadores como Jonathan Israel apuntan que el balance general de esta década no fue positivo para la Compañía de las Indias Occidentales. Los holandeses gastaron enormes cantidades de dinero y recursos y, aunque es cierto que consiguieron algunas grandes victorias como la toma de Salvador de Bahía o gestas tan importantes como la captura de la Flota de la Plata, lo cierto es que sus iniciativas no lograron nada de importancia - a nivel territorial o económico- en Brasil; es más, podría decirse que perdieron ventajas con las que anteriormente contaban ${ }^{45}$.

\section{DEL PILLAJE INDISCRIMINADO A LA CONQUISTA SELECTIVA: OLINDA Y EL HECHIZO DEL AZÚCAR PERNAMBUCANO}

Ahora que la compañía tenía a su disposición cerca de 100 navíos bien armados y 15000 soldados $^{46}$, en la mente de los holandeses volvía a aparecer Brasil como escenario perfecto para sus operaciones. Especialmente atractiva resultaba la toma de la Capitanía de Pernambuco y sus vecinas -Itamaracá, Paraíba y Rio Grande do Norte- por ser la mayor área de producción azucarera del mundo -658 mil toneladas $-{ }^{47}$.

Hay que tener en cuenta que Brasil, para inicios del siglo XVII, era un despropósito militar a nivel defensivo. Diogo de Campos Moreno, un veterano de la Guerra de Flandes, describía con minuciosidad los muchos puntos débiles que la capitanía pernambucana presentaba. Entre ellos la villa de Olinda ${ }^{48}$, municipio principal de la capitanía

43 Hemos de decir que tampoco aquí hay unanimidad con respecto a la cuantía del botín capturado. Cabral de Mello habla de ocho millones de florines, Jonathan Israel sostiene que fueron once los millones de florines y, por último, Wätjen habla de quince millones de Florines. En IsraEL, Jonathan I. La República Holandesa [...]. Op. cit. p. 175; en Wätjen, Hermann. O Dominio Colonial [...]. Op. cit. p. 93; y en Cabral de Mello, Evaldo. O Brasil holandés [...]. Op. cit. p. 41.

44 Guilherme M., Carlos; López, Adriana. Historia de Brasil [...]. Op. cit. p. 110.

45 Israel, Jonathan I. «El Brasil y la política holandesa [...]. Op. cit. p. 18.

46 WäTJen, Hermann. O Dominio Colonial [...]. Op. cit. p. 95.

47 Cabral de Mello, Evaldo. O Brasil holandés [...]. Op. cit. p. 41.

48 Situada en el estado de Pernambuco, Olinda fue fundada en el año 1535 por el capitán donatario 
y enclave marítimo que, sin embargo, podía ser fácilmente conquistado por cualquier armada mínimamente pertrechada que desembarcara en la playa de Pau Amarelo debido a sus escasas infraestructuras defensivas ${ }^{49}$.

Precisamente a Olinda fueron encaminados los pasos de la WIC, ya que las experiencias de la última década habían demostrado que Bahía sólo podía ser retenida con una guarnición permanente de grandes fuerzas y con una inversión importante por tierra y mar ${ }^{50}$. Así pues, la capital azucarera pernambucana se convirtió en el objeto de deseo de la Compañía de la Indias Occidentales, que no tardó en preparar una expedición. Cabral de Mello apunta que la decisión de atacar Pernambuco estaba ya tomada en 1628, pero no fue hasta finales de 1629 cuando cobró forma. Con esta empresa los Estados Generales dictaban el paso de una política de pillaje a una más agresiva y costosa de conquista; de hecho las instrucciones que se dieron a Hendrick Corleliszoon Loncq, que había sido el segundo de Heyn en Matanzas, fueron apoderarse de Pernambuco a la mayor brevedad y después encaminar los pasos hacia Santiago de $\mathrm{Cuba}^{51}$.

El 21 de diciembre de 1629 todos los preparativos estaban listos y la armada se encontraba reunida en San Vicente ${ }^{52}$. Según Johan de Laet la expedición estaba formada por 35 grandes naves y 30 de menor calado, con una tripulación total de 7280 hombres -3780 marineros y 3500 soldados- y un armamento que ascendía a 1170 cańones de todos los calibres ${ }^{53}$. Otras fuentes como Jonathan Israel o Cabral de Mello constatan que fueron 67 y no 65 las naves que componían la flota ${ }^{54}$. El mando de tan poderosa fuerza naval fue encomendado al almirante Loncq, mientras que la dirección de las fuerzas de tierra fue confiada al coronel Diederick van Waerdenburch, veterano de la Guerra de los Treinta Años.

En febrero de 1630 la armada llegó a Olinda, iniciándose un fuerte bombardeo sobre el puerto de Recife y una internada de la infantería holandesa -unos 3000 hombres- a través de la playa de Pau Amarelo ${ }^{55}$. La defensa de la zona estaba al cargo de Matías de Albuquerque, hermano del capitán donatario Duarte de Albuquerque

\footnotetext{
Duarte Coelho Pereira, siendo así una de las ciudades brasileñas más antiguas y una de las más importantes a comienzos del siglo XVII por su condición de sede administrativa de la Capitanía de Pernambuco y por el alto número de ingenios azucareros que la rodeaban. 
y superintendente de guerra en Pernambuco, quien ya estaba prevenido de la llegada de la flota y de la imposibilidad de recibir refuerzos o ayuda por parte de Madrid, ya que la hacienda de los Austrias estaba en un momento de pauperización extrema ${ }^{56}$. Las defensas luso-brasileñas resistieron como buenamente pudieron las primeros acometidas de los neerlandeses, pero era un conflicto cuyo resultado ya estaba definido antes de empezar la contienda. Con las escasas y mal preparadas tropas divididas entre Olinda y Recife, Matías no pudo soportar la situación de combate trabado que los holandeses plantearon en el río Doce ${ }^{57}$ y Olinda cayó con relativa facilidad. Las fuerzas de defensa tuvieron que replegarse y refugiarse en Recife, que por aquella época era una insignificante villa de pescadores con apenas $150 \mathrm{casas}^{58}$. Ante la imposibilidad de una victoria que cada vez se veía más lejana, se ordenó a las escasas tropas que aún resistían prender fuego a 24 navíos cargados con 8000 cajas de azúcar, gran cantidad de palo brasil, tabaco y algodón ${ }^{59}$. Además, en un intento final por repeler el ataque bátavo, Matías de Albuquerque ordenó incendiar los almacenes del puerto, ocasionando sustanciosas pérdidas. Duarte de Albuquerque estima, en sus Memórias diárias da guerra do Brasil de 1654, que de esta forma se quitaron de las manos del enemigo más de 4.000 .000 de cruzados $^{60}$. No obstante, pese a estos esfuerzos y a la fiereza con que se defendieron los fuertes de Recife de la pesada artillería enemiga, la superioridad del ejército de Waerdenburch, manifiesta desde el inicio del enfrentamiento, decantó definitivamente la balanza del lado de los invasores, quienes consiguieron rendir Recife de forma definitiva el 1 de marzo de $1630^{61}$.

Matías de Albuquerque y sus hombres huyeron hacia el interior, refugiándose en los ingenios y haciendas de la vega de Apipucos, próxima al litoral pernambucano ${ }^{62}$. Desde allí, los portugueses del nordeste de Brasil organizaron la resistencia en el fuerte del Bom Jesus, entre Recife y Olinda, y rehicieron sus maltrechas fuerzas para repeler los ataques holandeses y arrinconar a las tropas de la WIC en la costa, de tal suerte que sólo

56 Matías se dedicó a reparar y pertrechar los escasos fuertes de la zona y a preparar la resistencia con los insuficientes medios, humanos y técnicos, de que disponía. Wë́tjen, Hermann. O Domínio Colonial [...]. Op. cit. pp. 99-100.

57 Cabral de Mello, Evaldo. O Brasil holandés [...]. Op. cit. p. 53; Wätjen, Hermann. O Domínio Colonial [...]. Op. cit. p. 101.

58 Guilherme M., Carlos; López, Adriana. Historia de Brasil [...]. Op. cit. p. 110.

59 Estos datos son los que dan Guilherme Mota y Adriana López, sin embargo, Wätjen habla de una pérdida de 17000 cajas de azúcar. Wätjen, Hermann. O Domínio Colonial [...]. Op. cit. p. 102.

60 Albuquerque Coelho, Duarte de. Memórias diárias da guerra do Brasil [1630-1638]. Recife: Fundação de Cultura Cidade do Recife, 1981, pp. 51-52.

61 Gonsalves de Mello, José Antonio. João Fernandes Vieira: mestre de campo do têrço de infantaria de Pernambuco. Recife: Universidade do Recife, 1956, p. 29.

62 Guilherme M., Carlos; López, Adriana. Historia de Brasil [...]. Op. cit. p. 110. 
podían aprovisionarse por mar $^{63}$. Los invasores dominaban el puerto, la salida hacia el Atlántico y la ciudad, mientras que los colonos luso-brasileńos, auxiliados por precarios contingentes españoles y europeos, dominaban el interior, los campos de cultivo y el sistema productivo. A partir de ese momento los comandantes del ejército de ocupación intentaron, sin éxito, romper el cerco impuesto por las fuerzas de la resistencia y el conflicto fue adquiriendo visos claros de guerra europea de desgaste, algo muy parecido a lo que ocurría con los tercios espańoles en Flandes ${ }^{64}$.

Cuando la noticia de lo acaecido en Brasil llegó a Madrid y Lisboa, Olivares y sus ministros se lanzaron a una actividad frenética para preparar una contra-ofensiva arrolladora según el modelo de la de $1624^{65}$. Sin embargo, la ruinosa situación en los Países Bajos y en Italia impidó reaccionar con idéntica rapidez. En septiembre de 1631 se optó por el envío de tropas portuguesas, napolitanas y castellanas -unos 2000 efectivos de los cuales tan sólo llegaron $700^{66}$ - en una armada de auxilio, inferior a la de 1624, comandada por el experto almirante guipuzcoano don Antonio de Oquendo. Se inauguraba así el goteo sistemático de asistencias procedente de una metrópoli económicamente exhausta y más preocupada en contener el avance bátavo tierra adentro que en la expulsión holandesa definitiva ${ }^{67}$.

\section{LA FASE DE CONTRAGUERRILLA HOLANDESA, 1632-1635}

El impasse bélico provocado por la guerra de desgaste desarrollada tras la conquista de Olinda y su área circundante, en la Capitanía de Pernambuco, duró hasta 1632, momento en que la llegada de considerables refuerzos holandeses permitió a la compañía incrementar su actividad militar, consolidar sus posiciones y ampliar su cabeza de playa en Brasil de manera significativa.

Los comandantes bátavos tomaron, a partir de entonces, una actitud de contraguerrilla que se sustentó en su superioridad naval y en su movilidad, permitiéndoles atacar puntos distantes de la costa y amedrentar a la población local para que dejase de apoyar a las tropas luso-españolas ${ }^{68}$. De esta forma, entre 1633 y 1634 los holandeses, pese a seguir confinados en una estrecha franja de terreno que carecía de valor comercial,

\footnotetext{
63 Israel, Jonathan I. La República Holandesa [...]. Op. cit. p. 179.

64 Santos Pérez, José Manuel. «Estado, capitanías donatarias [...]. Op. cit. p. 96.

65 Israel, Jonathan I. La República Holandesa [...]. Op. cit. p. 179.

66 De estos 700 soldados, 300 se encontraban bajo las órdenes del Conde Bagnuolo. Ibidem.

67 Valladares, Rafael. «Las dos guerra de Pernambuco. La armada del Conde da Torre y la crisis del Portugal hispánico (1638-1641)». En Santos Pérez, José Manuel; Cabral de Souza, George F. El desafio holandés [...]. Op. cit. p. 36.

68 Cabral de Mello, Evaldo. O Brasil holandés [...]. Op. cit. p. 107.
} 
consiguieron romper las líneas de resistencia y progresar en el norte, apoderándose en 1633 del fuerte de Ceará y de la isla de Itamaracá ${ }^{69}$.

Poco a poco las tropas de la compañía comenzaron también a dominar la zona de Pernambuco y los coroneles Van Schoppe y Arciszewski, alemán y polaco respectivamente, empezaron a sacar partido del terreno tropical, modificando las tácticas militares y adaptando las estrategias bélicas a los requerimientos del entorno y a las características del enemigo. De esta forma, los holandeses comenzaron a desarrollar iniciativas de intimidación, ataques selectivos e incursiones relámpago en territorio enemigo con contingentes poco numerosos. Acciones, todas ellas, cuyo principal objetivo era infundir temor y sembrar el desconcierto entre las tropas luso-españolas y las guerrillas luso-brasileñas.

En el año 1635 las fuerzas de ocupación de la WIC consiguieron definitivamente romper el cerco: conquistaron Paraíba, derrotaron en Porto Calvo a una columna hispano-napolitana que se encontraba bajo el mando del Conde Bagnuolo, se apoderaron de Igaraçu, ocuparon Rio Grande do Norte y tomaron el cabo de Santo Agostinho, lugar por el que las tropas luso-españolas recibían los escasos refuerzos que llegaban de Madrid y Lisboa. Por último, ese mismo año también cayó, tras un asedio de casi tres meses y un intenso bombardeo, el Arraial de Bom Jesus, complejo defensivo portugués más importante de la región.

\section{EVOLUCIÓN Y ADAPTACIÓN DE LAS INICIATIVAS MILITARES Y LA ESTRATEGIA BÉLICA HOLANDESA EN BRASIL}

En vista de lo señalado hasta el momento, uno puede considerar que lo que se desarrolló en la Capitanía de Pernambuco durante estos años no fue sino el traslado ultramarino de un prolongado contenciosos entre dos potencias europeas enfrentadas. Sin embargo, aunque esta vez el escenario europeo se había cambiado por el colonial y lo que estaba en juego era el control del más importante territorio en producción azucarera del mundo, la realidad del conflicto fue algo más compleja. En esta contienda se dieron cita concepciones de guerra europea y estrategias militares enormemente parecidas por parte de la corona española y las fuerzas holandesas, unas técnicas e iniciativas bélicas que pronto mostraron su ineficacia sobre territorio brasileño y que obligaron a ambos contendientes a desarrollar adaptaciones constantes al medio.

En una primera fase, los holandeses volcaron todos sus esfuerzos en el impulso y desarrollo de una «guerra de fortalezas» al estilo europeo ${ }^{70}$, convencidos de que la

69 Guilherme M., Carlos; López, Adriana. Historia de Brasil [...]. Op. cit. p. 111.

70 Un modelo estratégico que concebía la fortaleza como base principal de operaciones y cuyos resultados habían sido más que satisfactorios en el litoral africano, donde construcciones militares tan importantes como el Fuerte Nassau, erigido en 1612 en la Costa del Oro, sirvieron de enclave 
conquista del litoral brasileño pasaba irremisiblemente por la construcción de un rosario de plazas fuertes que les daría la llave del control sobre el territorio ${ }^{71}$. Una estrategia bélica que en el período de 1630 a 1632 se mostró del todo equivocada. En estos ańos los holandeses se vieron acorralados y atrincherados en los fuertes, confinados al territorio costero, sin ningún poder sobre el entramado productivo brasileño y obligados a un derroche infructuoso de esfuerzos y fondos por parte de la $\mathrm{WIC}^{72}$. Con todo, podemos decir que este período -denominado de «guerra lenta» por algunos autores ${ }^{73}$ y durante el cual no hubo avances significativos en el devenir del conflicto- fue una versión, tropical si se quiere, de la Guerra de Flandes. Un enfrentamiento en el que las tropas neerlandesas y las hispano-lusas tuvieron desempeños y características idénticas: contingentes de mercenarios dirigidos por oficiales veteranos de las guerras europeas más o menos competentes, con una fuerte presencia de elementos locales que eran indisciplinados y poco fiables y con un fracaso claro de las tácticas militares europeas sobre terreno brasileño -ejemplo de ello es la desesperación y el desánimo que se cernía sobre las tropas de Bagnuolo al intentar arrastrar las piezas de artillería por los tortuosos caminos del litoral Pernambucano ${ }^{74}-$. $^{2}$

Sin embargo, con los progresos territoriales desarrollados a partir de 1632, otro tipo de guerra comenzó a desplegarse. Una fase de mayor dinamismo militar en la que los holandeses, pese a continuar resistiendo incursiones de carácter semi-guerrillero ${ }^{75}$ por parte de las tropas locales y luso-españolas, emprendieron iniciativas militares más acordes a los requerimientos bélicos del entorno, con una estrategia económico-militar basada en la revitalización de las plantaciones de azúcar de la región y en la consolidación definitiva de sus posiciones mediante iniciativas militares concretas, ataques selectivos o maniobras de intimidación ${ }^{76}$.

para desbancar el comercio portugués de la región. En Guilherme M., Carlos; López, Adriana. Historia de Brasil [...]. Op. cit. pp. 107-108.

71 Brito Freyre, Francisco de. Nova Lusitânia. Historia da guerra brasilica [1675]. Estudio por Gonsalves de Mello, José Antonio. Recife: Colección Pernambucana, vol. V, 1977, pp. 195233.

72 SAntos Pérez, José Manuel. «Estado, capitanías donatarias [...]. Op. cit. p. 96.

73 Llamada así porque en ella primaba la actitud defensiva y la táctica. Además, este tipo de guerra era la deseada por muchos pernambucanos que querían aumentar la posibilidad de recibir mercedes por parte de la corona. En Valladares, Rafael. «Las dos guerra de Pernambuco [...]. Op. cit. p. 39. Y en Valladares, Rafael. «Brasil: de la unión de coronas [...]. Op. cit. p. 30.

74 SAntos PÉrez, José Manuel. «Estado, capitanías donatarias [...]. Op. cit. p. 96.

75 Estrategia militar y de combate denominada por la herencia historiográfica como guerra brasílica que consistía en ataques lanzados por sorpresa contra los holandeses al estilo de emboscadas indígenas. En Valladares, Rafael. «Las dos guerra de Pernambuco [...]. Op. cit. p. 35.

76 Israel, Jonathan I. La República Holandesa [...]. Op. cit. p. 234. 


\section{CONSIDERACIONES FINALES}

La mayoría de los historiadores coinciden al concluir que, pese a los recursos empleados por la WIC y los enormes gastos derivados de la empresa brasileńa, los holandeses no lograron nada de importancia en Brasil durante los años veinte del siglo XVII ${ }^{77}$. Más bien estas acciones, que casi llevaron a la compañía a una quiebra total, obligaron a los bátavos a explotar el Atlántico sin invertir grandes cantidades de dinero en conquistas o violencia ${ }^{78}$. En estos ańos, hasta los más ardientes defensores de la compañía por acciones se replantearon la situación y la viabilidad de tan ambiciosa empresa. Tampoco puede obviarse que la situación de la Monarquía Ibérica era crítica, sus ejércitos agonizaban en el barrizal de Flandes y sus finanzas disminuían en un denodado intento por mantener y controlar un imperio cuyos dominios empezaban a ser inabarcables. Sin embargo, pese al visible agotamiento hispánico, los holandeses no supieron aprovechar la situación ni desarrollar una estrategia de intervención militar acorde con las exigencias del entorno y las características de un territorio, el brasileño, visto por muchos como la puerta a América y a sus inigualables riquezas.

Es cierto que la situación cambió ligeramente a raíz de la captura de la Flota Española de la Plata en Matanzas y que, entre 1630 y 1635, la compañía logró fondos suficientes para comenzar a conquistar progresivamente todos los distritos azucareros nororientales de Brasil. Sin embargo, pese a los logros militares de este lustro, el rédito y los beneficios de las empresas neerlandesas en la colonia luso-española no llegaron nunca a compensar los ingentes gastos derivados de la aventura atlántica emprendida por la Compañía de las Indias Occidentales ${ }^{79}$. Ni siquiera la consolidación de lo que a la postre sería el Brasil holandés de los años 40 consiguió mitigar unas pérdidas iniciales que lastraron, de forma prematura, el futuro de las iniciativas holandesas en la zona.

Bien mirados, los primeros años de la guerra librada entre los Estados Generales y los Austrias de Madrid por el control de Brasil no fueron sino la historia de cómo unos europeos -enzarzados desde hacía algunas décadas en un prolongado enfrentamiento-

\footnotetext{
77 Israel, Jonathan I. «El Brasil y la política holandesa [...]. Op. cit. p. 18.

78 Emmer, Pieter. «Los holandeses y el reto atlántico en el siglo XVII». En SAntos Pérez, José Manuel; Cabral De Souza, George F. El desafío holandés [...]. Op. cit. p. 25.

79 Desde el inicio de su actividad en 1623 hasta 1636, la WIC armó un total de 806 navíos y pertrechó a miles de hombres entre tripulantes y soldados. Los gastos derivados de armar y mantener tan descomunal flota y ejército sobrepasaron la cifra de 45 millones de florines, todo ello sin contar los costos derivados de la conquista y la ocupación de zonas como Pernambuco. Como contrapartida, en esos 13 años, la Compañía de las Indias Occidentales consiguió capturar nada menos que 547 navíos ibéricos, además de la Flota de la Plata en 1628; unas cifras a simple vista favorables, pero cuyo montante total no excedía los 37 millones de florines. Estas cantidades unidas a las deudas de la West-Indische Compagnie con sus accionistas flamencos hacía que la compañía presentase, a inicios de 1636, un débito acumulado de 18 millones de florines. En Guilherme M., Carlos; López, Adriana. Historia de Brasil [...]. Op. cit. p. 111.
} 
trataron de imponerse sobre otros en América y de cómo y por qué fracasaron. Un conflicto, en definitiva, que traspasó los límites del viejo continente y supuso una constante adaptación y un reto para ambos contendientes, que vieron cómo la guerra atravesó diversas fases en las que muchas estrategias y preceptos bélicos europeos se transformaron considerablemente hasta adaptarse a los requerimientos del exótico y atractivo Brasil.

\section{REFERENCIAS BIBLIOGRÁFICAS}

Albi de la Cuesta, Julio. De Pavía a Rocroi; los tercios de infantería española en los siglos XVI y XVII. Madrid: Balkan Editores, 1999.

Boxer, Charles Ralph. The Dutch in Brazil: 1624-1654. Oxford: Clarendon, 1957.

Cabral de Mello, Evaldo. O Brasil holandés. São Paulo: Penguin Classics, 2010.

Cabral de Mello, Evaldo. Olinda restaurada. Guerra e açucar no Nordeste, 16301654. Rio de Janeiro: Topbooks, 1975.

Emmer, Pieter. «Los holandeses y el reto atlántico en el siglo XVII». En Santos Pérez, José Manuel; Cabral de Souza, George F. El desafio holandés al dominio ibérico en Brasil en el siglo XVII. Salamanca: Universidad de Salamanca, 2006.

Gonsalves De Mello, José A. Fontes para a história do Brasil holandês. 2 vols. Recife: Cepe, 2004.

Guilherme M., Carlos; López, Adriana. Historia de Brasil: una interpretación. José Manuel Santos Pérez (trad.). Salamanca: Ediciones Universidad de Salamanca, 2009.

IsRaEL, Jonathan I. Dutch primacy in world trade, 1585-1740. Oxford: Clarendon Press, 1989.

IsRAeL, Jonathan I. "El Brasil y la política holandesa en el Nuevo Mundo». En Israel, Jonathan I. [et al.]. Acuarela de Brasil, 500 años después, seis ensayos sobre la realidad histórica y económica brasileña. Salamanca: Ediciones Universidad de Salamanca, 2000.

Israel, Jonathan I. La República Holandesa y el mundo hispánico, 1606-1661. Madrid: Nerea, 1997.

PArker, Geoffrey. España y los Países Bajos, 1559-1659. Madrid: Rialp, 1986. 
Santaella Stella, Roseli. Brasil durante el gobierno español; 1580-1640. Madrid: Fundación Histórica Tavera, 2000.

Santos Pérez, José Manuel; Cabral de Souza, George F. El desafío holandés al dominio ibérico en Brasil en el siglo XVII. Salamanca: Universidad de Salamanca, 2006.

Santos PÉrez, José Manuel. «Estado, capitanías donatarias y compañías comerciales». En Santos Pérez, José Manuel; Cabral de Souza, George F. El desafio holandés al dominio ibérico en Brasil en el siglo XVII. Salamanca: Universidad de Salamanca, 2006.

VAlladares, Rafael. «Brasil: de la unión de coronas a la crisis de Sacramento (1580-1680)». En Israel, Jonathan I. [et al.]. Acuarela de Brasil, 500 años después, seis ensayos sobre la realidad histórica y económica brasileña. Salamanca: Ediciones Universidad de Salamanca, 2000.

Valladares, Rafael. «Las dos guerra de Pernambuco. La armada del Conde da Torre y la crisis del Portugal hispánico (1638-1641)». En Santos Pérez, José Manuel; Cabral de Souza, George F. El desafio holandés al dominio ibérico en Brasil en el siglo XVII. Salamanca: Universidad de Salamanca, 2006.

Wätjen, Hermann. O Dominio Colonial Holandês no Brasil. Recife: Companhia Editora de Pernambuco, 2004.

\section{FUENTES}

Albuquerque Coelho, Duarte de. Memórias diárias da guerra do Brasil [16301638]. Recife: Fundação de Cultura Cidade do Recife, 1981.

Brito Freyre, Francisco de. Nova Lusitânia. Historia da guerra brasílica [1675]. Estudio por Gonsalves de Mello, José Antonio. Recife: Colección Pernambucana, vol. V, 1977.

Gonsalves de Mello, José Antonio. João Fernandes Vieira: mestre de campo do têrço de infantaria de Pernambuco. Recife: Universidade do Recife, 1956. 